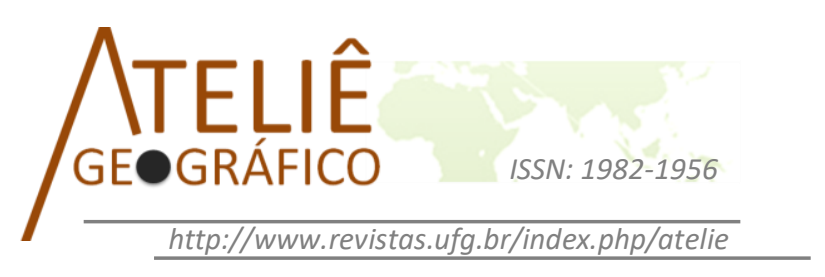

\title{
Notas sobre a migração campo-cidade e a monocultura no Brasil
}

\author{
Notes about rural-urban migration and monoculture in Brazil
}

\section{Notas sobre la migración rural-urbana y el monocultivo en Brasil}

\author{
Lucas Guedes Vilas Boas \\ Universidade Federal de Juiz de Fora \\ Centro Federal de Educação Tecnológica-MG \\ lucasgvb1991@hotmail.com
}

\begin{abstract}
Resumo
Este artigo discute a migração campo-cidade e a monocultura em território brasileiro, abordando aspectos vinculados às relações capitalistas de produção presentes no cenário agrário nacional. Assim sendo, serão aludidos processos como a mecanização agrícola, a Revolução Verde, a Modernização Agrícola, a especulação fundiária, entre outros. Para além, o direcionamento da produção agrícola ao exterior também será tema de discussão, pois compromete a segurança alimentar para a população brasileira. Outro fator deletério à alimentação é o fato de vastas extensões de terra serem utilizadas para a produção de agrocombustíveis ou de soja, voltada principalmente à alimentação do gado bovino. Neste contexto, a produção monocultora, atrelada ao uso intenso de agrotóxicos, reverbera em prejuízos à saúde dos brasileiros, pois reduz a variedade de gêneros alimentícios consumidos, além de ampliar a quantidade de enfermidades causadas pelo contato e ingestão dos pesticidas. Por fim, discute-se a questão agrária ante o processo de globalização e o neoliberalismo, os quais acentuam o viés capitalista presente na agricultura nacional, bem como na mundial.
\end{abstract}

Palavras-chave: Migração Campo-Cidade. Monocultura. Brasil.

\begin{abstract}
This article discusses the rural-urban migration and monoculture in Brazil, approaching aspects linked to capitalist relations of production present in the national agricultural scenario. Thus, will be alluded processes as agricultural mechanization, the Green Revolution, Agricultural Modernization, land speculation, among others. Furthermore, the direction of agricultural production abroad will also be theme of discussion, because prejudice the food security for the Brazilian population. Another deleterious effect to food is the fact that vast tracts of land be used for agrofuel production or soy production, mainly focused on feed cattle. In this context, monoculture production, linked to high use of pesticides, reverberates in damages to the health of Brazilians, because it reduces the variety of consumed foodstuffs, as well as expanding the number of illnesses caused by contact and
\end{abstract}


ingestion of pesticides. Finally, is discussed the agrarian question before the process of globalization and neoliberalism, which accentuate the capitalist feature present in national agriculture as well as in the world.

Keywords: Rural-Urban Migration. Monoculture. Brazil.

\section{Resumen}

Este artículo discute la migración rural-urbana y el monocultivo en Brasil, abordando los aspectos vinculados a las relaciones capitalistas de producción presentes en el escenario agrícola nacional. Así, serán aludidos procesos como la mecanización agrícola, la Revolución Verde, la modernización agrícola, la especulación del suelo, entre otros. Además, la orientación de la producción agrícola al exterior también será objeto de discusión, pues compromete la seguridad alimentaria de la población brasileña. Otro efecto perjudicial a la alimentación es el hecho de que grandes extensiones de tierra son usadas para la producción de agrocombustibles o soja, dirigida principalmente a la alimentación del ganado. En este contexto, la producción de monocultivos, vinculado a la utilización intensiva de pesticidas, reverbera en daños a la salud de los brasileños, pues reduce la variedad de alimentos consumidos, además de ampliar el número de enfermedades causadas por contacto e ingestión de pesticidas. Finalmente, se discute la cuestión agraria en el proceso de globalización y el neoliberalismo, los cuales acentúan la tendencia capitalista presente en la agricultura nacional, así como en el mundo.

Palabras clave: Migración Rural-Urbana. Monocultivo. Brasil.

\section{Introdução}

De antemão, é válido salientar que o texto versará sobre a migração campocidade e a produção monocultora no Brasil, visando ressaltar o inequívoco caráter capitalista presente na questão agrária nacional há anos. Neste âmbito, torna-se necessário elencar algumas dos principais aspectos do capitalismo agrário nacional. Apesar de seu vasto território, o acesso à terra no Brasil é caracterizado pela desigualdade, algo corroborado pelos elevados índices de concentração fundiária do país. Uma característica do capitalismo é o desigual acesso aos meios de produção.

Neste sentido, a estrutura fundiária nacional é marcada pelo alto número de latifúndios, os quais utilizam a ampla extensão territorial do país para aumento de suas lavouras monocultoras. A concentração de terras no Brasil também remete ao passado, visto que desde a colonização portuguesa, com as capitanias hereditárias e as sesmarias, a terra é dividida de modo díspar.

Os insumos urbano-industriais utilizados na agropecuária nacional são, em sua maioria, oriundos dos oligopólios transnacionais e multinacionais, os quais comandam a distribuição e a venda de elementos como maquinários agrícolas, pesticidas e sementes transgênicas. Inúmeras são as estratégias empreendidas por estas empresas para a manutenção do domínio neste setor, como a compra ou a fusão de empresas.

Ademais, no contexto de mundialização da agricultura, a agricultura nacional é pautada na exportação de commodities, as quais são cotadas nas Bolsas de Mercados de Futuros. Neste processo, os produtos primários são comercializados no mercado mundial para uso futuro. Deste modo, ante o capitalismo financeiro, a produção 
agrícola enquanto commodity se vincula à lógica da economia financeirizada, favorecendo a difusão de práticas capitalistas na agricultura.

Exemplo disto é a produção de soja, principal mercadoria de exportação do país. Na busca pela ampliação de seus lucros, os latifundiários sojicultores utilizam intensamente agrotóxicos e grãos transgênicos em suas lavouras, diminuindo a qualidade do alimento produzido e ampliando a insegurança alimentar, em prol do acréscimo nos índices de produtividade. Ressalta-se que a maioria da soja cultivada no Brasil não é destinada à alimentação da população brasileira. Além disto, em virtude da procura por fontes energéticas alternativas ao petróleo, percentual representativo das terras brasileiras é utilizado para a produção de agrocombustíveis, com destaque para os cultivos canavieiros orientados para a produção de etanol.

Destarte, almeja-se demonstrar como as relações capitalistas de produção impelem o pequeno proprietário à migração para as cidades, assim como discutir as causas e consequências da monocultura no país, a qual é voltada ao mercado externo, prejudicando a segurança alimentar em território nacional.

Inicialmente o artigo abordará a migração campo-cidade, dialogando sobre suas causas e consequências. Fenômenos como a mecanização da produção agrícola e sua consequente modernização, além da intensa especulação fundiária existente, contribuíram para acirrar a migração de pessoas do campo para a cidade em todo o território brasileiro. Tais fatos findaram por abarrotar as grandes urbes do país com trabalhadores desqualificados ${ }^{1}$ provenientes do campo, que em sua maioria, foram habitar as áreas mais pobres das cidades.

É imperativo enfatizar que os hábitos alimentares das pessoas são alterados com a mudança para as áreas urbanas e que o fato de não possuírem mais a propriedade do meio produtivo (a terra), as torna extremamente dependentes da renda salarial para asseverarem sua alimentação cotidiana. Assim, percebe-se como a chegada de relações capitalistas de produção no campo conduzem o trabalhador ao assalariamento, que é condição basal ao capitalismo, pois propicia maior exploração do trabalho e amplia expressivamente a extração de mais-valia.

Na segunda parte deste texto, discute-se o caráter monocultor da agricultura nacional, marcada pelos latifúndios que reduzem a produção a uma baixíssima diversidade e ainda voltam sua produção ao mercado externo, deteriorando assim o consumo de alimentos em escala nacional. Ressalta-se que as monoculturas, ao instaurarem uma débil variedade de alimentos em sua produção, agravam os quadros de insegurança alimentar e de fome, repercutindo em consequências deletérias à saúde humana.

\footnotetext{
${ }^{1}$ Deve-se sublinhar que a desqualificação à qual o trecho alude é referente ao nível de instrução, ou seja, aos anos de escolaridade destes trabalhadores. Contudo, isto não impede que eles sejam muito qualificados para algumas funções, por exemplo, o trabalho agrícola.
} 


\section{Metodologia}

Como aporte teórico-metodológico destes escritos, procedeu-se na análise de referências bibliográficas relativas à agricultura nacional, principalmente sobre as práticas agrícolas monocultoras instauradas no país, a migração campo-cidade e os mecanismos fomentadores de tal processo, como a Modernização Agrícola e a Revolução Verde, entre outros. Não obstante, também foram utilizados escritos de autores que discutem a problemática agrícola mundial, visto que esta reverbera diretamente no cenário agrário brasileiro.

Para além, alguns dados e informações fornecidos pelo Instituto Brasileiro de Geografia e Estatística (IBGE), referentes à dinâmica da população urbana e rural no país, foram utilizados no intuito de contribuir para as discussões realizadas sobre a migração campo-cidade em território nacional.

\section{Migração Campo-Cidade no Brasil}

Andrade (1979), à época de seus escritos, já corroborava a indissociabilidade entre campo e cidade, ao criticar as políticas que consideravam a cidade como um fator isolado e os estudos que apregoavam a dualidade campo/cidade. Para o autor, alguns problemas urbanos ocasionados pela intensa migração do campo para a cidade poderiam ser solucionados através de ações no campo.

Então, defende-se aqui, que o campo é condição, pressuposto para a cidade, que dele deriva, e vice-versa. Portanto, é impossível pensá-los de modo dicotômico, pois ao mesmo tempo em que constituem um par contraditório, possuem múltiplas imbricações e conexões, evidenciadas, por exemplo, pela dependência que a cidade ainda possui dos alimentos advindos do campo. Ratificando a estreita conexão entre urbe e campo, ao explanar acerca da cidade de Recife, Josué de Castro (1957-C, p. 70) escreve:

\footnotetext{
Por exemplo, não pode haver dúvida de que uma das causas diretas da miséria urbana do Recife é o estado de miséria rural condicionado pelo latifundiarismo da cana de açúcar. Na grande área do Estado, de monocultura açucareira, vive a população trabalhadora num estado agudo de pauperismo, resultado dos ínfimos salários pagos nesta zona.
}

Neste intervalo, o autor ressalva os liames existentes entre campo e cidade ao atrelar a miséria urbana à rural. Para ele, a concentração fundiária, apoiada no latifundiarismo monocultor, impõe deletérias condições de sobrevivência ao camponês, incitando-o à migração para a cidade. Consequentemente, é este pobre advindo da migração do campo que residirá nas periferias sociais das grandes urbes, constituintes de bolsões de miséria e pobreza extrema no país. Então, desgraçadamente, as desigualdades sociais que vigoram no campo são replicadas nas cidades, o mesmo princípio secular da concentração de renda do meio rural se observa de modo dramático nas cidades.

Como o migrante recém-chegado é desprovido de qualquer meio produtivo, se 
vê obrigado a vender sua força de trabalho a baixos preços para assegurar sua subsistência. Sua condição de pobreza não se altera, somente seu local de moradia. Ainda sobre a temática aventada, o autor tece a seguinte afirmação:

Êstes elementos aí chegando, sem armas técnicas de luta, nem reservas econômicas de nenhuma ordem, ficam durante certo tempo flutuando, desambientados no ritmo urbano e são levados, assim, pela necessidade, a improvisar uma moradia, que por imitação e facilidade natural de construção, é sempre o mocambo. Acresce a êsse contingente, o de retirantes, não mais do brejo, da zona das usinas, mas do alto sertão, assolado pelas sêcas. (CASTRO, Josué de. 1957-C, p. 69)

Em relação à assertiva aludida, ressalta-se que no litoral nordestino, a construção

de mocambos pela população de menor poder aquisitivo é uma prática corriqueira. Já em outras regiões do país, as dificuldades vivenciadas pelo migrante advindo do campo são desveladas ao analisar-se as demais periferias sociais, como as favelas.

A princípio, uma expressão da situação miserável destes migrantes é a dificuldade em conseguir um posto de emprego, devido à sua desqualificação profissional. Ademais, sem remuneração asseverada, sua receita é extremamente baixa e o impele a residir em áreas bastante degradadas, tanto socialmente, quanto fisicamente. Este quadro é evidenciado no município de Nepomuceno, localizado na mesorregião Sul/Sudoeste de Minas Gerais, cuja economia está assentada na cafeicultura. A maioria dos indivíduos nepomucenenses que migraram do campo para a cidade trabalham em uma indústria aviária, a qual emprega expressivo número de pessoas no município, pagando pequenas remunerações pelo trabalho por elas executado.

Isto justifica a ocupação intensa de áreas situadas em vertentes bastante acentuadas ou localizadas nas planícies de inundação de alguns corpos hídricos, assim como grandes aglomerações humanas em localidades onde predomina a violência e o medo impera, nas quais há o desamparo por parte das autoridades públicas, que buscam escamotear a situação através de medidas paliativas, principalmente em época eleitoral.

No âmbito da discussão realizada, a tabela 01 ilustra a variação da população urbana e rural no Brasil entre os anos de 1960 e 2010.

Tabela 1: População Urbana e Rural no Brasil de 1960 a 2010

\begin{tabular}{c|c|c|c|c|c}
\hline Ano & $\begin{array}{c}\text { População } \\
\text { Total }\end{array}$ & $\begin{array}{c}\text { População } \\
\text { Urbana }\end{array}$ & $\begin{array}{c}\text { Percentual da } \\
\text { População Urbana }\end{array}$ & $\begin{array}{c}\text { População } \\
\text { Rural }\end{array}$ & $\begin{array}{c}\text { Percentual da } \\
\text { População Rural }\end{array}$ \\
\hline $\mathbf{1 9 6 0}$ & 70.992 .343 & 32.004 .817 & $45,08 \%$ & 38.987 .526 & $54,92 \%$ \\
\hline $\mathbf{1 9 7 0}$ & 94.508 .583 & 52.904 .744 & $55,98 \%$ & 41.603 .839 & $44,02 \%$ \\
\hline $\mathbf{1 9 8 0}$ & 121.150 .573 & 82.013 .375 & $67,70 \%$ & 39.137 .198 & $32,30 \%$ \\
\hline $\mathbf{1 9 9 1}$ & 146.917 .459 & 110.875 .826 & $75,47 \%$ & 36.041 .633 & $24,53 \%$ \\
\hline $\mathbf{2 0 0 0}$ & 169.590 .693 & 137.755 .550 & $81,23 \%$ & 31.835 .143 & $18,77 \%$ \\
\hline $\mathbf{2 0 1 0}$ & 190.755 .799 & 160.925 .792 & $84,36 \%$ & 29.830 .007 & $15,64 \%$ \\
\hline
\end{tabular}

Fonte: IBGE (2010). 
As informações do IBGE demonstram que no decênio de 1960, a população urbana superou a população rural em território nacional. De acordo com os dados mostrados, a migração campo-cidade no Brasil foi intensa na segunda metade do século XX, caracteriza pela industrialização e urbanização de amplas regiões do país, apresentando redução expressiva a partir dos anos 2000.

Salienta-se que o Nordeste foi utilizado como exemplo para discutir a questão agrária nacional, pois conforme indica Darcy Ribeiro (1995), foi a primeira região ocupada do país, na qual se instalou a agricultura, sendo fornecedora de manancial humano para todo o Brasil. Nos dizeres do antropólogo, o nordestino povoou o território nacional.

Castro (1957-A) enuncia que os momentos de seca no sertão nordestino promoveram o acirramento da migração campo-cidade, com os sertanejos, desprovidos de água e alimentos, aventurando-se nas urbes. $\mathrm{O}$ autor enfatiza os empecilhos deste percurso de migração até a cidade, demonstrando que a fome, de caráter quantitativo ou qualitativo, devasta o sertanejo nestes momentos.

Neste sentido, é válido ressaltar, em consonância com as estatísticas divulgadas pelo Censo Demográfico do IBGE (IBGE, 2010), que o Nordeste é a região brasileira com maior população rural desde a década de 1960 até os dias recentes. De 1960 a 2010, seu quantitativo absoluto de população rural manteve-se praticamente o mesmo, com redução de apenas 3\%. Este estreito liame do povo nordestino com o campo é um dos elementos que justificam a ênfase conferida à região Nordeste no debate sobre a migração campo-cidade.

No tocante a esta questão, ao retratar o drama do sertanejo que migra por intermédio do personagem Juvêncio, Josué de Castro (1957-C, p. 52), em seu "Documentário do Nordeste", indaga: "Quando acabará esta sêca terrível? Qual acabará primeiro: a sêca ou a sua família? Que será melhor: morrer de fome e de sêde na sua própria terra ou emigrar para morrer de fadiga e de vergonha na terra dos outros?" Ainda referindo-se aos migrantes advindos do sertão, Castro (1957-A, p. 223) disserta:

\footnotetext{
Os que resistem às extenuantes caminhadas e chegam às terras úmidas dos brejos são as mais das vêzes atacados de graves doenças infectuosas, para as quais lhes falta a necessária imunidade, e morrem aos milhares. Em tôdas as grandes sêcas do Nordeste segue-se sempre à fome, a calamidade das pestes para completar o quadro da tragédia nordestina.
}

O intervalo ratifica o quão penoso é o trajeto percorrido por quem migra para as urbes. Demonstra também que a subnutrição favorece a proliferação de moléstias infecciosas, que praticamente não encontram nenhuma resistência nos corpos carcomidos pela alimentação precária e pelos sofrimentos da migração. No período em que escreve o autor, não era incomum visualizar-se corpos de defuntos espalhados pelo caminho entre o sertão e a cidade, sobretudo no percurso até a capital.

Em sua obra, Rachel de Queiroz destaca a religiosidade do sertanejo, quando 
comenta acerca das preces realizadas para "chamar" as chuvas. Em "O Quinze", seu primeiro romance, ela narra a história da seca de 1915, uma das mais graves ocorridas na região. Retrata também o drama do povo daquela terra, do retirante, suas dúvidas sobre soltar ou salvar o gado nos períodos de estiagem, entre outras questões. No intervalo abaixo, a autora (2010, p. 152) narra: "Reses famintas, esquálidas, magoavam o focinho no chão áspero, que o mato ainda tão curto mal cobria, procurando em vão apanhar nos dentes os brotos pequeninos."

No excerto, vê-se que os períodos de seca prolongada intensificam a migração para as urbes, pois agravam as condições de vida no semi-árido nordestino. $\mathrm{O}$ extrato da obra da romancista enfatiza alguns dos efeitos das longas estiagens, como a morte do gado e a redução da vegetação local. Com as lavouras praticamente extintas nestes árduos anos, além da drástica redução do rebanho bovino, base de seu modo de vida, os homens e mulheres do sertão são induzidos à migração para as áreas urbanas.

A mecanização agrícola atua no sentido de acentuar o processo aqui discutido, visto que ela substitui a força de trabalho humana. Quando o proprietário fundiário não precisa mais da mão de obra agrícola, esta se vê impelida a migrar para as urbes, em busca de emprego. Reclus (1985, p 144) enuncia que: "Os proprietários moralistas dão conselhos ridículos aos camponeses para que se mantenham ligados à terra, enquanto suas ações desenraizam o camponês e the criam condições de vida que o obrigam a fugir para a cidade."

Esta assertiva, extraída da fala de Reclus, permite vislumbrar que os discursos dos senhores da terra não condizem com suas ações. Enquanto eles diziam aos trabalhadores do campo para permanecerem em dado pedaço de solo, suas atitudes visivelmente os induziam à migração para as áreas urbanas, pois as condições de vida a eles oferecidas eram degradantes.

Outro fator corroborante da indissociabilidade entre campo e cidade é descrito por Andrade (1979), ao salientar a concentração de trabalhadores rurais residindo nas periferias (sociais) das urbes, sendo estes denominados de bóias-frias, devido à refeição levada para alimentação no local de trabalho, não aquecida antes da ingestão. $\mathrm{O}$ transporte destes proletários rurais é muito precário, expondo-os a inúmeras situações de risco e ampliando a insegurança destes.

A intensificação da migração campo-cidade, datada sobretudo da segunda metade do século XX, possui como consequência evidente o crescimento demasiado das urbes no Brasil, principalmente as metrópoles, que padecem com problemas relacionados à mobilidade urbana, à pobreza, à violência, entre outros.

Segundo Graziano da Silva (2001), aproximadamente um terço dos trabalhadores rurais no Brasil exercem atividades não-agrícolas, dentre as quais, as funções de caseiros, motoristas, pedreiros, entre outras. Nos últimos anos antecessores à pesquisa realizada por ele, o número de postos de trabalho não-agrícola cresceu no campo, enquanto houve redução do emprego agrícola nas áreas rurais, devido à 
mecanização da produção agrícola, agravante do desemprego rural no país.

O migrante advindo do campo, em geral, possui ínfima qualificação profissional, o que o impele a subempregos ou empregos de baixa remuneração. Como os seus proventos muitas vezes não são suficientes para lhe garantir condições adequadas de moradia, frequentemente vai residir em áreas de periferia social.

Não obstante, conforme pronuncia Graziano da Silva (2001), a migração do campo em direção à cidade no Brasil não é algo fatal, visto que nos últimos anos a população camponesa no país manteve-se praticamente estável. Enquanto isto, a população ocupada em práticas agrícolas sofreu expressiva redução nos últimos anos, indicando segundo o autor, um êxodo agrícola, ao qual julga como inevitável.

O caso de Nepomuceno corrobora a situação descrita pelo autor. Nos últimos anos, muitos moradores do campo nepomucenense trocaram o trabalho nas lavouras pelo emprego em um aviário do município. Na contextura municipal, o número de trabalhadores que trocou as atividades agrícolas por empregos urbano-industriais é significativamente maior que o quantitativo de indivíduos que migraram do campo para a cidade.

As informações apresentadas pelo IBGE, sintetizadas na tabela 01, ratificam os dizeres de Graziano da Silva (2001), pois demonstram que entre 2000 e 2010 houve pequena redução da população rural no Brasil, tanto em termos absolutos, quanto em valores percentuais. Assim sendo, a diminuição da população residente no campo neste decênio foi menor em comparação às décadas anteriores, indicando uma atenuação da migração campo-cidade no país.

Segundo as informações do último Censo Demográfico realizado pelo IBGE (2010) no ano de 2010, a redução da população rural no país entre 2000 e 2010 foi significativamente menor se comparada aos decênios anteriores. Em termos relativos ou percentuais, ainda houve grande decréscimo da população residente no campo no Brasil, devido ao elevado crescimento da população urbana. Já em termos absolutos, esta diminuição da população rural não teve tanta relevância como nos anos anteriores.

Todavia, torna-se importante salientar que as condições urbanas, mesmo antes da intensificação da migração campo-cidade no século XX, sempre foram precárias, agravadas pelas razões históricas já aventadas. Segundo Andrade (2004), as pequenas cidades e vilas brasileiras no período colonial e imperial, já apresentavam as mesmas características da desigualdade social que vigoravam no campo.

\section{Monocultura Direcionada à Exportação}

No Brasil, a sociedade agrária foi constituída de modo que os proprietários de terras, utilizando mão-de-obra escrava indígena (minoritária) e negra (majoritária), produzissem alimentos direcionados ao mercado externo, enquanto que os gêneros de subsistência eram tidos como de menor importância. $\mathrm{O}$ fato descrito prossegue existindo até os dias coevos, com a produção agrícola nacional ainda visando o 
exterior, enquanto os produtos de menor qualidade ficam no país para suprimento do mercado interno.

Deste modo, destaca-se que desde o período colonial, sempre se priorizou a agricultura volvida à exportação, em detrimento da voltada ao mercado interno. No início da colonização, produzia-se no Brasil para abastecer o mercado europeu. Por mais absurdo que pareça, transcorridos aproximadamente cinco séculos, tal situação persiste a mesma.

Porém, a agricultura de exportação, conforme expõe Andrade (1979), não assegurava estabilidade ao sistema econômico, o qual poderia variar segundo as leis de oferta e demanda no mercado internacional, bem como pelo crescimento da concorrência. No caso do açúcar, a concorrência do açúcar produzido pelos holandeses nas Antilhas fora crucial para a decadência deste gênero agrícola no cenário brasileiro.

Apesar de muitos autores, entre eles economistas e historiadores, dividirem a História Econômica do Brasil em ciclos, julga-se isso como algo equivocado, pois conforme assevera Andrade (1979, p. 72), estes são: "Ciclos que, na realidade, não existiram porque as culturas de exportação, quando perdiam importância na economia nacional, não deixavam de ser cultivadas nas áreas nelas especializadas.”

Exemplo nítido da questão aventada é o caso do açúcar no Brasil, que apesar do declínio após a concorrência das Antilhas, continuou sendo produzido no território nacional, tendo aumentos e quedas em sua produção, mas nunca deixando de ser cultivado, constituindo-se ainda como um dos principais produtos de exportação do país.

Assim sendo, tornam-se necessários alguns comentários sobre o decurso da cultura canavieira no Brasil, pois o açúcar foi o primeiro gênero agrícola produzido em larga escala no país, corroborando o viés empresarial da agricultura nacional, assentada na monocultura e voltada ao mercado externo. Neste âmbito, a cana-de-açúcar é usada como exemplo para demonstrar o percurso histórico da monocultura no Brasil.

Neste contexto, o primeiro produto impactante na agricultura nacional foi a cana-de-açúcar, cultivada sobretudo próxima ao litoral nordestino, primeira área largamente ocupada do país. Versando sobre este ponto, Freyre (1961) disserta que apesar da nítida divisão entre senhores e escravos na esfera do trabalho no setor canavieiro, no nordeste brasileiro o hibridismo foi intenso, devido à expressiva miscigenação entre brancos, negros, indígenas e mestiços. $\mathrm{O}$ autor salientou a indispensabilidade do negro para a civilização açucareira e o fato de a monocultura canavieira ter extinguido as lavouras de subsistência. Observou também que a monocultura acentuou a erosão dos solos, dirimindo destarte, sua fertilidade.

Brandão (1985) expõe que Duarte Coelho, então administrador da capitania de Pernambuco, obteve o capital necessário à instalação dos primeiros canaviais no litoral nordestino. Freyre (1961) relata que Duarte Coelho, o primeiro donatário da capitania hereditária de Pernambuco, já compreendia que o africano era o homem ideal para 
lavrar suas terras com cana de açúcar. Sobre a questão canavieira no país, Reclus (1900, p. 424) escreve:

\begin{abstract}
Tempo houve em que foi o Brasil que forneceu ao mundo maior quantidade de assucar; mas de 150 annos a esta parte perdeu a primasia em proveito das Antilhas, que a conservaram depois; a capitania de S. Vicente, para ode Martim Afonso de Sousa levou a canna da Madeira na primeira metade do século XVI, só tem hoje plantações sem importância. Atualmente a indústria açucareira está sobretudo representada em Pernambuco, na Bahia, e nos Estados vizinhos; o município de Campos, no Estado do Rio, entrega-se especialmente à cultura da canna, e em parte nenhuma se encontram usinas mais bem apparelhadas para a producção de assucares.
\end{abstract}

Em sua fala, o geógrafo francês exprime a existência da cultura canavieira na região de Campos (RJ), já no século XIX. Brandão (1985) explica que essa área tem cultivos de cana-de-açúcar desde o século XVII, mas só teve realce no setor há poucos anos. No entanto, as lavouras canavieiras existentes na região retrocitada direcionam-se majoritariamente à produção alcooleira.

O próprio Brandão (1985) demonstra que, embora a construção de um engenho fosse onerosa, seus rendimentos eram elevadíssimos, conferindo lucratividade ao seu senhor. Acerca da cultura canavieira e das usinas produtoras de açúcar, João Cabral de Melo Neto (2009, p. 35), em seu poema "O Rio”, relata que:

\author{
Vira usinas comer \\ as terras que iam encontrando; \\ com grandes canaviais \\ todas as várzeas ocupando. \\ O canavial é a boca \\ com que primeiro vão devorando \\ matas e capoeiras, \\ pastos e cercados; \\ com que devoram a terra \\ onde um homem plantou seu roçado; \\ depois os poucos metros \\ onde ele plantou sua casa
}

A passagem aludida corrobora o viés monocultor da cultura de cana-de-açúcar instalada no território nordestino, que além de gerar elevada degradação ambiental em virtude do desmatamento da vegetação nativa, também expandiu a concentração fundiária na região, ocupando terras outrora destinadas à agricultura camponesa e voltadas à subsistência.

Castro (1957-A) narra que a área canavieira do litoral nordestino era uma floresta tropical (a Mata Atlântica), transformada em campos abertos pelos engenhos e latifúndios. O autor acentua a elevada fertilidade do solo desta região, do tipo 
massapê ${ }^{2}$, e o clima propício ao cultivo de diversos alimentos, tanto originais do território brasileiro, quanto provenientes de outros pontos do planeta.

Freyre (1961) exalta a qualidade do solo massapê para a cultura canavieira, ao qual afirmou propiciar a garantia de muitas gerações de senhores de engenho, mostrando que esta se desenvolveu sob a tríade latifundiarismo - monocultura escravidão. Com relação a estes três aspectos, Castro (1957-B, p. 497-498) pronuncia:

\begin{abstract}
A exploração latifundiária, a monocultura à base dos salários baixos, apresentada em suas variantes nas áreas coloniais do mundo inteiro, constituem, pois, o caldo de cultura ideal para desenvolvimento do pauperismo, da miséria e da fome. Baseando sua economia em um ou dois produtos de exportação cujos preços foram sempre fixados pelas metrópoles consumidoras e tendo que importar uma infinidade de produtos industriais com preços pré-fixados pela metrópole, os povos coloniais tinham que permanecer atolados no pauperismo. Só com sua libertação econômica da política colonial poderão essas áreas de fome desenvolver sua produtividade, de forma a dispor do suficiente para o seu sustento,o que é possível, não só pela diversificação de sua produção, como também pela fixação do justo preço das matérias-primas e pelo seu beneficiamento industrial in loco.
\end{abstract}

No excerto destacado, assinala-se a associação existente entre monoculturas e exploração do trabalhador, devido às baixas remunerações pagas. Embora as nações subdesenvolvidas não sejam mais colônias, as relações de colonialidade ainda permanecem. Países periféricos, como os da América Latina, da África Subsaariana e do sul da Ásia prosseguem como fornecedores de matérias-primas às nações centrais, sendo dominados economicamente por estas.

Somente quando esta situação de dominância e dependência for eliminada, os países de economia frágil poderão desenvolver uma agricultura que fortaleça suas autonomias e beneficie seus habitantes, minimizando os casos de fome e de insegurança alimentar em seus territórios.

De modo análogo à fala de Freyre, Reclus (1900) enaltece a fertilidade do solo brasileiro, em âmbito geral, narrando que ao final do século XIX, o pequeno agricultor tupiniquim era nômade, pois migrava de terra cultivada conforme os solos iam se esgotando. Contudo, ele frisa que este uso excessivo e intenso do solo já ocasionara a redução da fertilidade em algumas partes do país, com elevada perda de nutrientes.

Nesta esfera, Castro (1957-A) expõe que ao implantar a monocultura canavieira, o colonizador luso sacrificou as possibilidades de outras culturas nas proximidades da costa nordestina, colaborando para o aumento de problemas alimentares em seus habitantes. $\mathrm{O}$ autor advoga também que a destruição da vegetação nativa e da fauna também contribuiu para minorar os recursos alimentícios da região,

\footnotetext{
${ }^{2}$ Os solos do tipo massapê são originados pela decomposição do granito, gnaisse, entre outras rochas, e possuem alto teor de argila em sua composição. Sua coloração é mais escura, além de serem ideais às práticas agrícolas por serem fertilíssimos. Esta elevada fertilidade deve-se em parte ao seu alto teor de matéria orgânica.
} 
porquanto ambos eram componentes do regime alimentar básico dos nativos. Obviamente, a alimentação ali tinha açúcares em excesso e era pobre em outros nutrientes.

Outro problema por ele apontado é a exaustão dos solos e seu consequente decréscimo de fertilidade, ocasionados pela monocultura da cana-de-açúcar. Deve-se grifar a relação existente entre tal fato e o comércio de açúcar, pois este era promissor no período, visto como uma especiaria. Os portugueses sabiam que a cultura canavieira só seria lucrativa se disseminada em larga escala. Para tal intento, deveriam ter elevada disponibilidade de terra e mão-de-obra. Referindo-se às muitas exigências impostas pela monocultura canavieira, Josué de Castro (1957-A, p. 103) profere que uma de suas características é a:

\begin{abstract}
De exigir uma escravidão tremendamente dura, não só do homem mas também da terra a seu serviço. Homem e terra que tiveram de despojar inúmeras prerrogativas para satisfazer o apetite desadorado da cana. Apetite insaciável de terras bem preparadas e bem drenadas para o crescimento da planta.
\end{abstract}

O excerto supracitado ratifica o caráter devastador desta cultura para o nordeste do país, pois ela degradou solos, vegetações e principalmente seres humanos nesta região. Concernindo a esta questão, ao dissertar sobre a certeza que o personagem Vicente possuía da inutilidade de seu serviço, Rachel de Queiroz (2010, p. 124) enuncia:

\footnotetext{
Em vão, mal amanhecia, iniciava a labuta sem descanso, e atravessava o dia todo no denso vaivém do serviço sem tréguas, cavando aqui uma cacimba, consumindo partidos do caroço de algodão, levantando, com as próprias mãos, que o labor corajoso endureceu, as reses caídas de fraqueza e de sede.
}

O trecho supramencionado ilustra a incessante rotina de labor desempenhada pelos moradores do sertão nordestino durante os dias em que a ausência de chuvas assola seus pedaços de terra e suas vidas. A estes homens e mulheres não há alternativas viáveis. Ou se entregam aos malefícios da escassez hídrica, permanecendo em suas terras, ou arriscam-se em difíceis migrações, nas quais muitos deles falecem devido aos empecilhos do percurso aliados às deficiências nutricionais de seus corpos carcomidos pela alimentação precária. Aqueles que, porventura, conseguiram alcançar a meta de chegar às grandes cidades, foram emparedados pela ausência de terras para cultivarem e pela precisão de se submeterem a desgastantes jornadas de trabalho para garantir a subsistência.

A partir da segunda metade do século $\mathrm{XX}$, as monoculturas que outrora se destinavam à produção de alimentos, foram direcionadas à geração de agrobiocombustíveis, agravando a questão da restrita diversidade de gêneros alimentícios cultivados em território nacional.

Ainda remetendo às lavouras canavieiras, vale ressaltar que na década de 
1970, com a Crise do Petróleo ${ }^{3}$, houve uma mudança no perfil energético mundial, pois em virtude da elevação do preço do barril, as nações procuraram alternativas energéticas, sobretudo renováveis. Neste contexto, o Proálcool foi criado pelo governo brasileiro no ano de 1975, visando substituir a gasolina pelo álcool (etanol) enquanto fonte de energia. À época, a gasolina era o derivado do petróleo mais consumido no Brasil. Salienta-se aqui, que neste momento histórico, o Brasil não era autossuficiente na produção petrolífera.

Brandão (1985) enuncia que o Proálcool foi um incentivo à cultura canavieira no Brasil. Criado durante o governo Geisel, além da questão energética, o programa pretendia trazer desenvolvimento ao país, mormente nos setores social, tecnológico e econômico. Foi implantado em locais que já possuíam usinas de cana-de-açúcar, como as unidades federativas do Nordeste e os estados de São Paulo e Rio de Janeiro.

Nos anos 1970, o açúcar brasileiro estava em baixa no mercado internacional, favorecendo o investimento no setor alcooleiro. As metas do Proálcool foram alcançadas no ano de 1990. Alguns estudiosos afirmam que o programa aumentou a concentração fundiária, favorecendo os latifúndios monocultores de cana-de-açúcar. Outro problema dele foi o fato de o álcool ter substituído somente a gasolina enquanto combustível, não conseguindo ser uma alternativa ao diesel.

Não obstante, existem autores com visões diferentes e até mesmo opostas sobre este programa governamental. Bautista Vidal (1997) apregoa que utilizando-se um pequeno percentual das terras disponíveis no Brasil para o plantio de florestas energéticas, a energia produzida equivaleria àquela resultante da queima de bilhões de barris de petróleo. Por conseguinte, para o autor, o uso de porções do solo nacional para o plantio de vegetais para fabricação de energia é algo viável, pois não comprometeria o suprimento de alimentos à população. Neste sentido, ele advoga que o uso da biomassa como fonte de energia no Brasil não acarretará na escassez de alimentos para a população, pois $3 \%$ do território nacional já seriam suficientes para produzir alimentos a toda a população nacional.

\footnotetext{
${ }^{3} \mathrm{Na}$ década de 1970, o mundo vivencia um período de recessão econômica, conhecido como Crise do Petróleo. Alguns autores dividem o período em $1^{\mathrm{a}} \mathrm{e} 2^{\mathrm{a}}$ Crises do Petróleo. Com relação à primeira crise do petróleo, sua principal causa foi a Guerra do Yon Kippur, que provocou um grande aumento do preço do barril de petróleo (mais que triplicou) no Oriente Médio. O encarecimento do petróleo ocorreu devido ao fato de que os países membros da OPEP (Organização dos Países Exportadores de Petróleo), a maioria localizando-se no Oriente Médio, recusaram-se a vender petróleo aos países que apoiaram Israel no conflito, como é o caso dos Estados Unidos. Isso motivou com que as nações mais industrializadas do mundo acirrassem a busca por novas fontes de energia alternativas ao petróleo. Acerca da Guerra do Yon Kippur, cabem algumas considerações. Logo após a famosa Guerra de Seis Dias, o governo israelense tomou medidas com a intenção principal de proteger as terras conquistadas, sobretudo o controle conquistado sob o Canal de Suez, importante na questão comercial e geopolítica naquele momento. O Yon Kippur é um feriado judaico, no qual se comemora o "dia do perdão". No ano de 1973, quando os israelenses comemoravam o dia do Yon Kippur, foram surpreendidos pelos ataques egípcios e sírios próximos à região do canal de Suez. Inicialmente, os árabes conseguiram facilmente invadir o Canal de Suez. Contando com um exército incomensuravelmente mais forte, Israel revidou e conseguiu vencer os árabes neste conflito. Esse episódio acirrou as tensões e as rivalidades no denominado "Mundo Árabe".
} 
Ele ainda defende que o uso da biomassa como fonte energética no Brasil geraria mais empregos e proporcionaria maior valorização do trabalhador rural. Para além, descentralizaria a economia, dinamizando várias regiões, visto que o plantio das matérias-primas e a geração da energia pela biomassa não seriam restritos a apenas um local, mas, seriam diversificados de acordo com as plantas nativas de cada área.

Isto minoraria a dependência que o país possui, sobretudo em termos econômicos, em relação a certos locais, como as metrópoles, além de trazer maior uniformidade na ocupação do país, ocasionando o povoamento de regiões até então com baixa densidade demográfica. Desta maneira, para Bautista Vidal (1997), o uso da biomassa como fonte de energia no Brasil, em larga escala, minoraria as disparidades existentes entre as regiões no território nacional.

Para além, o autor aponta a influência do setor financeiro e das multinacionais na economia brasileira como uma das causas do relativo insucesso do Proálcool em âmbito nacional, pois muitas empresas automobilísticas pautam sua produção em veículos movidos a gasolina ou óleo diesel.

Bautista Vidal (1997) ainda exprime que a biomassa existente em abundância na região intertropical permite a obtenção de diversas fontes energéticas renováveis, como o álcool, por exemplo. Neste sentido, ele indica o óleo do coco de dendê, o coco de babaçu e o carvão vegetal como ótimas alternativas de fontes energéticas renováveis existentes no país.

Para ele, a região intertropical é por si só, autossustentável, sendo capaz de suprir várias necessidades globais, como a energética e a alimentar. Para isto, são necessários planejamentos estatais descentralizadores, que visem o bem-estar de suas populações. Segundo o autor, a biomassa no Brasil deve ser protegida pelo Estado, o qual deve controlar o seu processo produtivo, para evitar que as grandes corporações também dominem essas novas fontes de energia.

De acordo com Marques (2011), a partir dos anos 2000, os agrocombustíveis ganham realce no cenário mundial, como alternativa viável para a substituição dos combustíveis fósseis, devido à finitude e ao alto grau de poluição causado por estes, entre outros aspectos. Os debates em torno da polêmica questão do aquecimento global também colaboraram para o ganho de importância e o crescimento na produção das fontes energéticas de origem vegetal.

A agricultura mundial tem vivenciado uma série de crises nos últimos anos, com alta recorde dos preços de óleos vegetais, muito usados para fins energéticos. Tal situação ameaça a segurança alimentar global. Os principais impactados são os pobres, sobretudo nos países em desenvolvimento, que destinam expressiva parcela de seu PIB (Produto Interno Bruto) ao setor energético, crucial para o desenvolvimento econômico e industrial. Em âmbito internacional, o mercado dos biocombustíveis tem crescido muito, em parte graças aos incentivos governamentais, fomentadores de pesquisas, de técnicas e da produção nesta área. 
O uso de vastas extensões de terra para o cultivo de gêneros utilizados como matéria-prima para fins energéticos pode acarretar no acréscimo dos índices de insegurança alimentar, pois parcela significativa do solo que poderia ser usada para a produção de alimentos direcionados ao consumo dos seres humanos não é utilizada neste intuito.

Contudo, nos tempos recentes, os Estados destinam preocupação e esforços ao setor energético, visto que este repercute diretamente na economia nacional, sendo um dos aspectos mais influentes para o crescimento econômico de um país. Exemplo disto é o caso brasileiro, no qual o governo, desde o decênio de 1970, em virtude da Crise do Petróleo, investe maciçamente na pesquisa e na produção de fontes energéticas de origem vegetal, como o álcool proveniente da cana-de-açúcar, o biodiesel derivado do óleo de mamona, entre outras. Os esforços efetivados pelo governo brasileiro na questão energética resultaram na criação do Proálcool, já discutido nas páginas anteriores. Acerca deste, Bautista Vidal (1997, p. 140) afirma:

\begin{abstract}
A existência do Programa Nacional do Álcool, com uma ampla estrutura já quase totalmente ressarcida, distribuída por todo o território nacional, com domínio tecnológico único e o mais avançado, dá ao Brasil condição excepcional de ter uma solução autônoma que o possibilita salvar-se de uma crise energética mundial nesse crucial setor, podendo também ser suporte para outros países, incluindo potências econômicas muito vulneráveis.
\end{abstract}

Portanto, o Proálcool surge no Brasil como uma possível solução para a crise econômica de proporções mundiais. Conforme manifesta o autor, as Crises do Petróleo de 1973 e de 1979 alertaram para a finitude dos combustíveis fósseis e de seus derivados. Ademais, o atual modelo energético brasileiro é profundamente centralizador e submisso, pois é concentrado em poucas localidades no país, além de depender intensamente do capital estrangeiro.

Conforme indica McMichael (2009), a dependência do capitalismo industrial em relação aos agrocombustíveis é uma das culpadas da atual crise alimentar. Segundo o autor, os países do Sudeste Asiático e da América Latina (entre eles, o Brasil) estão expandindo a área produtora e a quantidade total produzida de gêneros agrícolas destinados à questão energética. Ademais, ele analisa que países como Índia, Paquistão, Ucrânia, Argentina e China, estão arquitetando medidas protecionistas para assegurar a aquisição de grãos e fertilizantes, aspirando garantir a segurança alimentar da população.

Quanto ao panorama nacional, Bravo (2007) ressalta os maciços investimentos realizados pelo Estado brasileiro no intuito de liderar o mercado global de agrocombustíveis. Salientando a importância conferida pelo governo brasileiro ao setor, a autora expõe que aproximadamente $60 \%$ da produção de etanol derivado da cana-deaçúcar provêm do Brasil, onde mais da metade da área ocupada pelo cultivo canavieiro é destinada à produção alcooleira. Neste enredo, em 1989, o governo nacional 
promulgou uma lei que tornou obrigatória a adição de 20 a 25\% de álcool na gasolina.

Porto-Gonçalves e Alentejano (2010) pronunciam que, nos anos recentes, tem ocorrido no campo brasileiro a substituição de culturas de arroz, feijão e milho por plantios de cana-de-açúcar. As regiões mais afetadas são o oeste do estado de São Paulo, o sul de Goiás e o Triângulo Mineiro. Com isto, há a diminuição da produção e da oferta destes alimentos à população, e o deslocamento de seus cultivos para terras mais longínquas e de menor fertilidade. Todos estes fatores contribuem para elevar o preço final destes alimentos, visto que o custo de produção tornou-se mais oneroso, bem como o de transporte.

Na década de 1960, quando a crise econômica afetou o Brasil, o país elevou sua produção de soja, pois devido à altíssima dívida externa, optou por produzir gêneros bem aceitos no mercado internacional. De acordo com dados do IBGE (2013), nos tempos atuais, a sojicultura ocupa praticamente $38 \%$ das terras cultivadas por todo o território nacional e é responsável por $29,7 \%$ do valor total da produção agrícola do país. A figura 1 é ilustrativo no sentido de demonstrar o expressivo acréscimo na área e na produção de soja no Brasil.

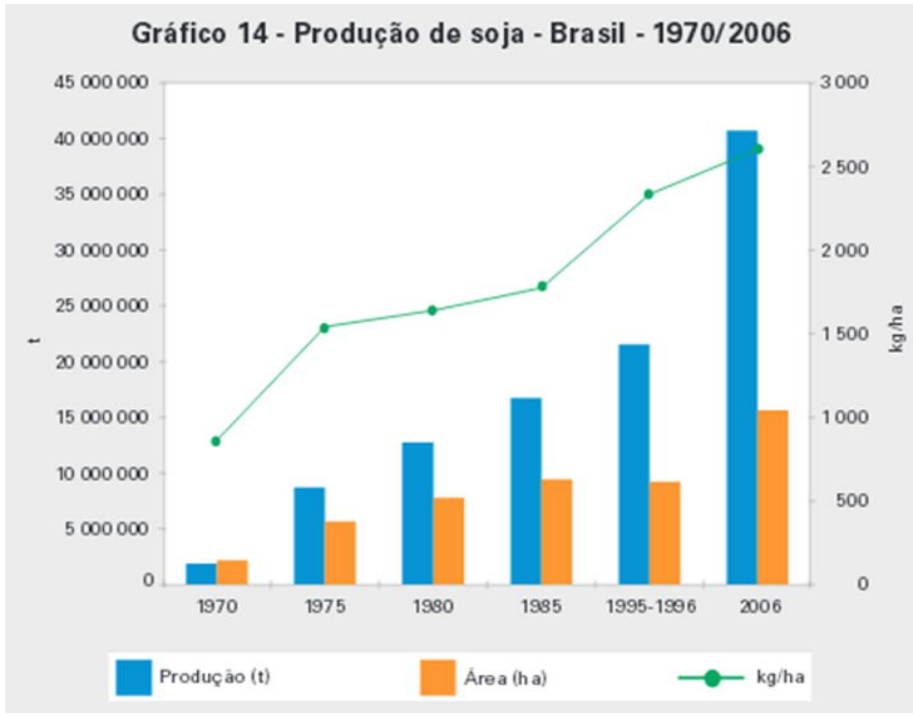

Figura 1. Produção de Soja no Brasil de 1970 a 2006. Fonte: IBGE (2006).

Os dados fornecidos pelo IBGE (2006) denotam o crescimento da produção de soja no país, cujo quantitativo aumentou mais de $1000 \%$ em 36 anos. Destarte, a cultura da soja foi implantada em muitas unidades federativas do país e em inúmeros locais onde outrora se cultivava o feijão, alimento indispensável à dieta da população brasileira. 
Tal fato incidiu na necessidade de importar feijão, o que encareceu o preço da dieta básica do brasileiro, influindo na economia e na qualidade de vida da população. Isso corrobora o fato de que a produção alimentícia brasileira é voltada à exportação e varia conforme as oscilações e os desejos do mercado global, segundo ratificam autores como Oliveira (2007), Alentejano (2012), Valverde (1980), entre outros.

Porto-Gonçalves e Alentejano (2010), bem como Hiath (2009), dissertam que, com a urbanização, houve o aumento do consumo de carne. Consequentemente, também ocorreu a elevação na demanda por grãos, sobretudo milho e soja, principalmente para alimentação de rebanhos bovinos. Percentual representativo da produção agrícola de alguns países mundo afora é dedicado a esta finalidade.

Atualmente, é maior o consumo de alimentos direcionado aos animais, do que o consumo humano, mesmo considerando aquele voltado a finalidades energéticas. Os autores supracitados destacam o aumento do rebanho bovino nas últimas décadas no Brasil, já superando o quantitativo de população humana no país.

Cana, soja e milho são produtos típicos da agricultura empresarial, voltada à produção de combustíveis ou à alimentação de animais. Nos últimos anos, houve significativo acréscimo na área destinada a estas culturas no Brasil, enquanto que a área direcionada ao plantio de arroz, feijão e mandioca, produtos indispensáveis na dieta do brasileiro, foi reduzida.

Criticando o enfoque produtivo do agronegócio, Porto-Gonçalves e Alentejano (2010) afirmam que a produção de alimentos deve volver-se aos alimentos básicos. Ademais, devem existir políticas e mecanismos de garantia da aquisição dos alimentos e de preços acessíveis, de modo a alargar a segurança alimentar da população.

Em Nepomuceno, mesmo os indivíduos que possuem porções de terra disponíveis para o cultivo enfrentam quadros de insegurança alimentar, pois a maioria dos pequenos proprietários agrícolas municipais baseia sua produção na monocultura cafeeira. Em muitos casos, não há sequer o plantio de outros gêneros alimentícios sem fins lucrativos, voltado à alimentação da própria família.

Não obstante, salienta-se que a agricultura de cunho empresarial, baseada nas monoculturas, é nociva à segurança alimentar da população brasileira, pois nela predominam a agricultura extensiva e as lavouras temporárias, visto que elas variam conforme as modificações do mercado e o interesse dos empresários do setor agrícola, os quais visam o lucro. Nos últimos anos, o agronegócio tem vivido um período de esplendor no Brasil, país que apresenta os maiores índices de crescimento neste setor.

No tocante ao assunto, Vergopoulos (1977) expõe que a agricultura, submetida ao capitalismo, recebe os fluxos de capitais, de rendas e de trabalhadores, promovendo a circulação destes na forma de mercadorias componentes do sistema mecanizado. Esta assertiva do autor mostra a amálgama existente entre modo de produção capitalista, mecanização da agricultura e agronegócio. Por conseguinte, ao engendrar estratégias para a ampliação dos lucros na agropecuária, os capitalistas disseminam a monocultura 
em escala mundial, reduzindo a diversidade de víveres cultivados.

No município de Nepomuceno, as grandes corporações transnacionais e multinacionais constituem monopólios e oligopólios, pois dominam a venda de insumos urbano-industriais, tais como pesticidas, sementes transgênicas e máquinas agrícolas, aos pequenos agricultores locais. Esta situação corrobora os dizeres de Costa Neto (1998), nos quais o autor advoga que as práticas capitalistas permeiam a agricultura camponesa, inclusive a pequena produção destinada ao abastecimento do mercado interno. Como o pequeno agricultor depende de sua produção para a subsistência, o modo de produção capitalista arquiteta estratégias que o impelem ao aumento da produtividade, algo almejado pelos capitalistas.

Para além, a agricultura nepomucenense é pautada na cafeicultura, a qual está presente na maioria dos imóveis agrícolas do município. Neste sentido, o café produzido em Nepomuceno é repassado às cooperativas cafeeiras atuantes no município, as quais negociam o produto nas Bolsas de Mercados de Futuros. Assim sendo, o café municipal é uma commodity, visto que está inserido na lógica especulativa da economia financeirizada e tem sua cotação decidida pelo mercado internacional.

Porto-Gonçalves e Alentejano (2009) retratam o viés moderno-colonial vigente no agronegócio brasileiro, explicitando como este se alicerça na concentração fundiária e na violência para manter suas relações de poder. Os geógrafos salientam que as ações violentas no campo são praticadas tanto pelo poder público, quanto pelo privado, principalmente no intuito de amortizar movimentos de resistência camponesa, na luta por maior equidade no acesso à terra ou pela menor exploração do proletário agrícola.

Os autores relatam que nos últimos anos, o Estado brasileiro executou um elevado número de despejos de famílias das terras ocupadas, principalmente nas porções de solo vinculadas ao agronegócio ou sob a posse de grandes corporações industriais. Tal situação é uma amostra de como o governo age, constituindo-se em instrumento de reprodução da propriedade privada e da concentração fundiária. $\mathrm{O}$ Estado concretiza ações em prol da expansão do agronegócio e reprime as ocupações de terras, através dos despejos judiciais. Desta maneira, ele se opõe aos movimentos sociais do campo e perpetua a colonialidade no setor agrícola do país.

Portanto, as ações governamentais, ao favorecerem os interesses capitalistas no campo brasileiro, dificultam a permanência no meio rural, estimulando a migração em direção às urbes e atuando na ampliação da concentração de terras. Para sua expansão, o agronegócio carece da incorporação constante de novas terras e utiliza mecanismos mercantis, políticos e violentos para isto. Por conseguinte, evidencia-se que a modernização agrícola foi caracterizada pelo predomínio dos interesses latifundiários associados aos dos capitalistas industriais, bem como pela violência na defesa de seus interesses. Destarte, a modernização encontra-se entrelaçada à 
colonialidade no campo nacional.

O desenvolvimento da agropecuária empresarial e dos complexos agroindustriais, alicerçados em práticas monocultoras, coexiste com o trabalho escravo no campo brasileiro, como o existente no aviamento realizado nos seringais e carvoarias, e com a exploração do proletariado rural. Frequentemente, as agressões e assassinatos cometidos no campo nacional são uma tentativa de silenciar e enfraquecer aqueles que desagradam os interesses dos grandes capitalistas e proprietários fundiários. Tais atitudes podem ser equiparadas àquelas efetuadas pelos senhores de terras no início do período colonial brasileiro, ambicionando a manutenção do poder, como a perseguição aos quilombos e aos movimentos contrários às oligarquias agrárias, entre outras.

\section{Considerações Finais}

A agricultura está densamente atrelada à saúde humana, pois ela é base da alimentação da maioria dos grupos humanos. Portanto, é fundamental para a subsistência dos homens e mulheres na superfície terrestre, visto que fornece os nutrientes necessários ao funcionamento do organismo humano, promovendo assim o bom desempenho de suas funções vitais.

Ademais, vale ressaltar que a agricultura, principalmente quando submetida às exigências do modo de produção capitalista, é uma das atividades trabalhistas mais insalubres. Inúmeros são os males aos quais os trabalhadores agrícolas se expõem no local de trabalho, tanto devido às intempéries (exposição à radiação solar e às precipitações intensas, muitas vezes sem a proteção adequada), como devido aos riscos de manuseio de instrumentos de trabalho e de produção, visto que muitos não utilizam os equipamentos de proteção individual (EPI's), entre outros perigos.

Neste âmbito, a migração campo-cidade e a produção monocultora são características indiscutíveis do panorama agrário brasileiro, densamente marcado pelas relações de cunho capitalista. Associados à elevada concentração fundiária e ao latifundiarismo, impelem o pequeno proprietário à migração para as cidades. Para além, sua produção é direcionada ao mercado externo e visa o acréscimo na produtividade, em detrimento da qualidade dos gêneros cultivados.

\section{Referências Bibliográficas}

ALENTEJANO, Paulo. "Estrutura Fundiária.” In: Dicionário da Educação do Campo. CALDART, Roseli Salete; PEREIRA, Isabel Brasil; ALENTEJANO, Paulo; FRIGOTTO, Gaudêncio. (Orgs.) Rio de Janeiro/São Paulo: Escola Politécnica de Saúde Joaquim Venâncio. Editora Expressão Popular, 2012. p. 353-358.

ANDRADE, Manuel Correia de. Agricultura \& Capitalismo. São Paulo: Livraria Editora Ciências Humanas, 1979.

. A Questão do Território no Brasil. 2 ${ }^{\text {a }}$ Edição. São Paulo: Editora Hucitec, 
2004.

BAUTISTA VIDAL, J. W. A Reconquista do Brasil. Rio de Janeiro: Espaço Tempo, 1997.

BRANDÃO, Adelino. Cana de açúcar: álcool e açúcar na história e no desenvolvimento social do Brasil. Brasília: Editora Horizonte, 1985.

BRAVO, Elizabeth. Agrocombustíveis, Cultivos Energéticos e Soberania Alimentar na América Latina - aquecendo o debate sobre agrocombustíveis. São Paulo: Editora Expressão Popular, 2007.

CASTRO, Josué de. Geografia Da Fome. $5^{\text {a }}$ edição, São Paulo: Editora Brasiliense, 1957-A.

. Geopolítica Da Fome. 4a edição, São Paulo: Editora Brasiliense, 1957-B.

. Documentário do Nordeste. São Paulo: Editora Brasiliense, 1957-C.

COSTA NETO, Canrobert. Agricultura Familiar e Renda da Terra. Estudos Sociedade e Agricultura, n. 10, 1998, p. 118-134.

FREYRE, Gilberto. Nordeste. $3^{a}$ Edição. Rio de Janeiro: Livraria José Olympio Editôra, 1961.

GRAZIANO DA SILVA, José. Velhos e novos mitos do rural brasileiro. Estudos Avançados. Vol. 15 (43). 2001, p. 37-50.

HIATH, Marcos. Terra dos Homens, Terra da Fome: Ensaio Relacionando a Obra de Josué de Castro com a Assimétrica Geopolítica da Carne. In: Anais do XIX Encontro Nacional de Geografia Agrária. São Paulo. 2009, p. 01-18.

IBGE - Instituto Brasileiro de Geografia E Estatística. Censo Agropecuário - 2006. 2006.

. Censo Demográfico de 2010. 2010.

. Produção Agrícola Municipal - Culturas temporárias e permanentes. Vol.

40. Rio de Janeiro. 2013.

MARQUES, Marta Inez Medeiros. O Novo Significado da Questão Agrária. Texto de Apoio ao Curso de Graduação em Geografia. São Paulo: USP, 2011. Disponível em: <http://www.geografia.fflch.usp.br/graduacao/apoio/Apoio/Apoio_Marta/2011/2semest re/8_Marques_questao>

MCMICHAEL, Philip. A food regime analysis of the 'world food crisis'. Agricultural Human Values. Vol. 26, 2009, p. 281-295.

MELO NETO, João Cabral de. "O Rio”. In: Morte e vida severina: e outros poemas. Rio de Janeiro: Editora Objetiva, 2009, p. 15-54.

OLIVEIRA, Ariovaldo Umbelino de. Modo Capitalista de Produção, Agricultura e Reforma Agrária. $1^{a}$ Edição. São Paulo: FFLCH/ Labur Edições, 2007.

PORTO-GONÇALVES, Carlos Walter. A Globalização da Natureza e a Natureza da 
Globalização. Rio de Janeiro: Editora Civilização Brasileira, 2006.

PORTO-GONÇALVES, Carlos Walter. ; ALENTEJANO, Paulo. A Violência do Latifúndio Moderno-Colonial e do Agronegócio nos Últimos 25 Anos. Conflitos no Campo Brasil. 2009, p. 109-118.

, Paulo. Geografía Agraria de la Crisis de los Alimentos en Brasil. Mundo Siglo XXI - Revista del Centro de Investigaciones Económicas, Administrativas y Sociales del Instituto Politécnico Nacional. Vol. 20, 2010, p. 39-54.

QUEIROZ, Rachel de. O Quinze. 87 Edição. Rio de Janeiro: Editora José Olympio, 2010.

RECLUS, Éliseé. Estados Unidos DO BRASIL - Geographia, Ethnographia, Estatística. Tradução: B. F. Ramiz Galvão. Rio de Janeiro/Paris: H. Garnier, LivreiroEditor. 1900.

. "O Problema Urbano.” In: Éliseé Reclus (Org. ANDRADE, Manuel Correia de). São Paulo: Editora Ática. 1985, p. 143-166.

RIBEIRO, Darcy. O Povo Brasileiro. $2^{a}$ Edição. São Paulo: Companhia das Letras, 1995.

VALVERDE, Orlando. "Metodologia da Geografia Agrária”. In: Reflexões Sobre a Geografia. São Paulo: Edições AGB São Paulo, 1980, p. 53-80.

VERGOPOULOS, Kostas. "Capitalismo disforme (O caso da agricultura no capitalismo)". In: A Questão Agrária e O Capitalismo. AMIN, Samir. \& VERGOPOULOS, Kostas. Tradução: Beatriz Resende. Rio de Janeiro: Editora Paz e Terra, 1977. p. 43-179.

\section{Lucas Guedes Vilas Boas}

Licenciado e Bacharel em Geografia pela Universidade Federal de Juiz de Fora. Especialista e Mestre em Geografia pela Universidade Federal de Juiz de Fora. Atualmente é prrofessor de Geografia do CEFET/MG.

Avenida Monsenhor Luiz de Gonzaga. Centro. 37250000 - Nepomuceno, MG Brasil

E-mail: lucasgvb1991@hotmail.com 